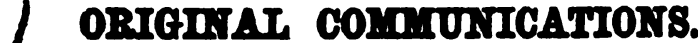

\section{FRACTURE, AND EXCISION OF THE ENDS OF BONES; ALSO VARIOUS RESULTS OF INJURIES TO BONES.}

\section{By J. RUSSEEL, Esq.}

I. FRACTURE, AND EXCISION OF THE ENDS OF BONES.

Soxr of the following cases of fracture and excision of the ends of bones are reported to illustrate the practicability of confining separated and very moveable portions of bone by means of ligature applied immediately to the ends; and others, to show different results of similar injuries, when attended by different complications. The idea of applying direct mechanical means of control to the ends of bones, in very moveable cases of fracture, was suggested to my mind while treating Case $\nabla$ undermentioned, which happened in 1839. I adopted it in Case I undermentioned; and the case having terminated so satisfactorily, I communicated the principal features of it to the late Mr. Liston, and from him I learned that the use of wire ligature in bone was not altogether new; but I remained ignorant of any farther statistics of its use till August 1852, when I learned from the Lancet that it had been used by Dr. Valentine Mott, of Philadelphir, in 1826; and that it had also been used by M. Flaubert, of Rouen, at some subsequent period. The paragraph alluded to was quoted from the British and Foreign Medico-Chirurgical Review for July 1852; and upon referring to that journal, I found the following stated at page 133. It is a review of part of an essay upon the value of seton as a remedy in ununited fractures, contributed by Dr. Mott to the New York Academy of Medicine, and is as follows:- "The fifth case was an ununited fracture of the os brachii, of eight months' standing, in a boy aged twelve; the fragments being conical, and separated from each other by at least an inch. Two setons were passed at intervals, and respectively maintained for several months, without any benefit resulting; the ends of the bone were now sawn off, and a silver wire passed through each, twisted, and brought out externally through a canula. The wire cut out from one of the bones in a few days, and the other was soon after removed. No great inflammation followed, and in a few weeks consolidation was complete." This case occurred in 1826, and is regarded by Dr. Mott as the first in which the ends of the bone have been brought into contact by the wire suture. Since then it has been repeatedly employed with success by the New York surgeons. It was thus employed several years prior to its adoption by Flaubert of Rouen, to whom Malgaigne attributes its origin.

Dr. Mott believes that the seton will be usually found to succeed when the bones are in contact or very nearly so; and that, when they are not so, no operation promises better than that of resection of the fragments, and their anion by means of wire.

I will now proceed to describe the principal features of the cases which have occurred in my own practice, and then offer a few remarks on the utility and modus operandi of ligature in bone.

CASE I. William Bennett, aged nine years, was brought to me about Christmas 1843. I was told that his injury had been received twenty-seven weeks previously. He had an ununited fracture of the humerus, at the point of junction of the middle and lower thirds. It was perfectly pliable; so that, when the upper arm was attempted to be raised to a horizontal position, the lower portion of the humerus, with the forearm, hung perpendicularly. Many fragments of bone had escaped during the progress of the case. The wounds had healed. A free incision was made on the outside of the arm, where the lower portion of bone was very prominent. I exposed the ends, and removed their points, endeavouring to do so at a point which would leave the denuded ends with a surface of the size of the natural cinanmfarence of the bone. The lower portion had pene- trated and united to the triceps muscle. The onds of the bone were rery pointed, and were connected by ligament; and a third detached portion, about half an inch long, was included in the ligament. I drilled a canal obliquely in each end, in the cylindrical portion of the bone, which terminated at about an inch from the ends. A piece of platins wire was passed through the canals, and twisted into a ligature. A slight degree of fever ensued, which lasted a few days. Very little suppuration took place, and the ligature separated on the thirteenth day, perfectly free from any exfoliated bone, and uncorroded. The bone united in the ordinary period, a month; no exfoliation followed, and the wound healed readily. The patient had in 1849 a good, firm, and useful arm, and was earning his living as a haulier in a colliery.

This case was reported in the Lancet, July 13th, 1850.

Casn II. Rees Jones, collier, aged 49, applied to me April 18th, 1851, with disease of the right elbow joint: it was far adranced and extremely painful. There were wounds, which discharged freely. Accumulations of matter occurred from time to time, and free incisions were made for its escape, but no relief followed. He was very much emaciated; but he declared that he was not much thinner than he used to be, and that he had been a tolerably healthy man through life. These two last statements, I was afterwards told, were not correct, he having been a sickly man for many years. He was anxious that some operation should be performed, if possible, without losing his arm. As it appeared probable that the emaciation proceeded from the continual suffering and drain from his arm, excision of the joint was performed on May 30th. Canals were drilled in the cylindrical portion of the bones, and a piece of strong twine was passed through, and the bones were brought together by tying it tightly. The arm continued very painful after the operation, and, about the end of seventeen days, the ligature remaining firm, it was cut through and removed. No relief followed. But the pain continued severe and constant, and the arm was amputated at about the middle of the humerus in August. The ends of the bones were found corered by a gelatinous pulp, and rough and carious. The pain continued to affect the stump. He was also subject to violent attacks of pain, which he referred to the right side of the abdomen. He gradually grew worse, and died in May, ten months after the removal of the arm.

Exaxiration of the Bony. On opening the chest, the lungs presented one uniform black mass, which appeared to result from spurious melanosis. The intestines were amassed by cohesions. The liver was of the ordinary size, but, upon being cut into, presented a mottled nutmeg-like appearance.

CAsE III. John Williams, aged 58, a railway haulier, fractured his leg Nov. 6th, 1852, from his foot becoming entangled in the wheel of a loaded waggon while endearouring to unfix it. The tibia was fractured obliquely at the junction of the middle and lower third. No apparent injury had occurred to the skin. The limb was set, and put up in the ordinary way, with side splints.

Nov. 7th. He had suffered great pain. The leg was corered with vesicles; most of them were filled with a dark coloured fluid. The foot was of low temperature. There was but little constitutional disturbance. Warmth was ordered to be constantly applied.

Nov. 8th. The foot had recovered warmth; the vesicles were subsiding; and a distinctly marked slough, about two inches in diameter, was present over the seat of fracture.

Nor. 22nd. The slough was removed, and the prominent pointed extremity of the lower portion of the tibia could be seen in the centre of the wound, and much raised. It was denuded of periosteum, and blanched.

Nov. 23rd. After enlarging the wound, I removed by the saw the points of both upper and lower portions. Upon again examining the wound, an isolated large piece of bone was discovered lying at the back part of the wound, strongly held by the interosseous ligament, and required much force for its disengagement. Canals were then bored 


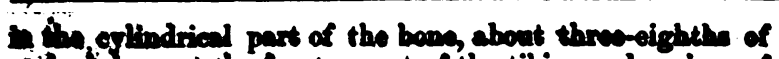
1. bed long at the froent aspect of the tibia ; and a pince of coper wiro (No. 16) was paseed through them, and twisted thity, till the ends of the bone came firmly in contact. Ino Imb was placed on a pillow, and supported at the sider.

Nov. 28th. Ererything had progressed favourably. The lower portion of bone had fallen slightly backwards, but wis easily raised by the ligature. The ligature appeared slightly loosened.

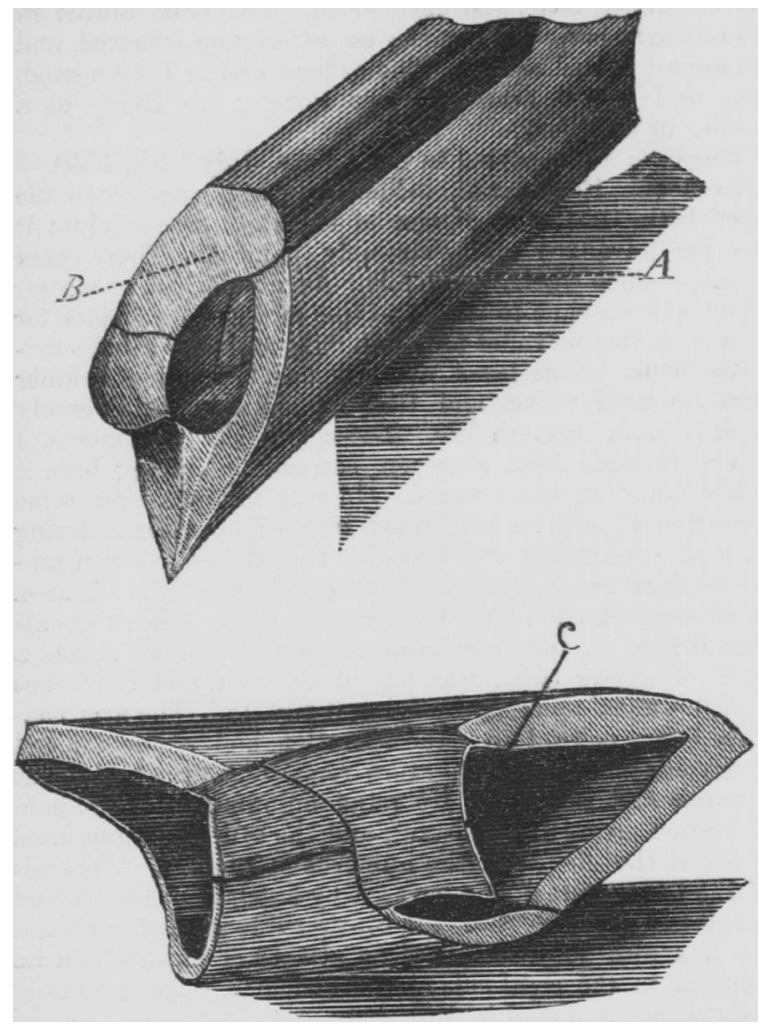

Sketch of the pieces of bone trken from John Williams 's leg. A. Piece of bone attuched to interosseons ligament, two iuches and threequar:ers long. B. Snwn surface. C. Sawn surface; a small portion

missing. The two sawn surfaces were one inch and a-quarter apart.

Nov. 30th. The ligature was decidedly loose, and a small piece of exfoliated bone, about the size of a grain of rock powder, came away from the side of it. Exfoliation was still going on from the lower portion.

Dec. 2nd. The upper portion, as well as the medulla were granulating bealthily: the granulations surrounded the wire closely.

Dec. 3rd. The lower portion had again fallen back a fourth of an inch, and was apparently released from the ligature.

Dec. 4th. The ligature came away altogether by using very small force. It was free from any attachments, uncorroded, and not altered in any respect.

Dec. 5th. The bones were connected by a band of granulations, which could be stretched by extending the leg.

Dec. 7th. He was progressing favourably. A collection of matter had formed over the lower end of the fibula. The limb supported itself while lying on a pillow.

Dec. 13th. Firm union was advancing, and everything had progressed favourably since the last report.

Jan. 3rd, 1853. The wound was filling up. By grasping the leg above the seat of fracture, and raising it, it raised and supported the lower portion.

Jan. 13th. Union was quite firm. The limb was taken cut of the cradle, and laid unsupported on a pillow. An abmoen formed upon the heel during the severe renther, and the roands healed slowly; but everything continued to

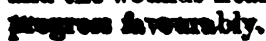

In Auguat 1863, the log might be aid to be peroetly sound, and the chape remartiably good. It was the linetres shorter then its fellow.

CasE IV. Lewis Evans, aged 22, complained of an afreo tion of his elbow about Christmes 1851-52. His right foot had been previously affectod, and at present there is an open sore on it. Counter-irritation and constitutional treatment were pursued; but suppuration took place, and wounds opened about the elbow-joint, about twelvemonths ago; and scrofulous disease of the joint was rery evident. The wounds and discharge continued, and about last Christmas the idea of excision of the joint was entertained; but his constitution appeared so much impaired that it was not thought advisable to operate then. Many of his family are the subjects of scrofula in various forms. One has disease of the hip-joint, and one died of phthisis. Twelve months afterwands, the disease of the elbow and the constitutional symptoms appeared to be much the same, and to have been stationary for the last six months; and the wounds having put on a more healthy appearance, and the arm remaining useless and helpless, so much so as to require the assistance of its fellow for all movements, excision was determined on.

The operation was performed June 14th, 1853. The humerus was found to have lost its periosteum for a considerable distance, and a large portion of bone was required to be removed. After removing the olecranon, a doep rough notch could be felt on the anterior aspect of the ulna, about a quarter of an inch from the sawn end. This required the removal of a second piece from the ulna. The radius appeared sound. Holes were then bored through the cylindrical part of the bone, perpendicularly or nearly so, into the medullary cavity or centre of the cancellated structure. Common bottling wire was then passed double through the holes, and twisted till the ulna and humerus appeared to be in contact. Iittle constitutional disturbance followed the operation. On the second day, a very obtusely angular splint was applied to the inside of the arm.

June 15th. The splint was discontinued.

June 17th. The patient walked to my house, a distance of five hundred yards.

July 14th. The ligature was quite firm. No pain was caused by pulling it. The wounds were granulating and healing.

July 15th. A large portion of the wound healed; the ligature romained as before. The thickening round the humerus was decreasing.

July 18th. He had felt considerable pain in his arm the day before, apparently caused by a small abscess over the former site of the internal condyle. I pulled very hard at the ligature, which was still firmly attached, which caused no pain. He had no return of pain.

July 21 st. The wounds continued to heal fast. The ligature still endured a hard pull without yielding. The arm continued easy.

Aug. 3rd. The ligature continuing sound, it was pulled very hard, and yielded about half an inch; very probably released from one bone. A quill was then passed through a loop in the wire, and a quantity of worsted was twisted round between the quill and arm.

Aug. 6th. The worsted had made a great depression. The wire was untwisted, and, while attempting to pull it out, it became released altogether. The arm was gradually acquiring strength, and the wounds were healing.

Aug. 14th. The upper arm was much inflamed, swollen, and hand; an abscess pointed in front of the head of the radius, and was opened.

Aug. 17th. I free discharge of pus had taken place, and the arm was altogether much improved.

Aug. 19th. The arm was much better.

Aug. 30th. The patient continued to improve. The thickening of the humerus and the enlargement of the arm, generally, were diminishing.

Sept. 26th. Several mall wounds were still opm. Ito patient oonld now raise his axm, and touch his upter lip with his themb, vanainted 
Pnuser I will now offer for considerntion the most pring points, a they appear to me, of the foregoing cases, and $m$ deductions from them The object which Dr. Mott ar M. Fluubert had in view when they finst adopted the use of wire lignture in cases of ununited fracture, does not appear from the above sccount; nevertheless, whether it was need as a connecting agent only, or with the object of exciting action in the ends of the bones, is, I think, not matorial. The object at which it is desirable to arrive is that which experience proves or renders probable. In the sixth case of Dr. Mott, the expression occurs, "joined by means of iron wire". In the ninth case (which he considers s unique, it being an example of intra-uterine non-union), we find the words, "and connected them with silver wire"; and part of the concluding sentence of the report is "resection of the fragments, and their union by means of wire". In all these cases, the wire appears prominent as an agent of connexion. My observations lead me to conclude that no action farourable to the union of bone is caused by the presence of the ligature. I view it as a perfect parallel to ligature and sutures in other living structures; and I believe that none think the presence of sutures in the integument or elsewhere favourable to healing otherwise than as an agent of approximation. In Case III, the bones and wire were exposed to view, and the granulations from the bone clocely surrounded the wire, which was copper; and no pain appeared to be caused by pulling the wire, which had remained in the bone long enough to have produced irritation, if calculated to do so. And in Case Iv, the frequent and hard pulls produced no more sensation than to allow the patient to acknowledge that he felt it. In Case I, the boy complained of a pricking pain for a part of the time of the presence of the wire in his arm, which I think, from its nature, may be justly referred to an angle in the wire. In Case II, the patient suffered excessive pain, which had existed previous to the operation, and continued after the removal of the ligature, and even after the amputation of the limb; and the man's condition of body was, I think, sufficient to account for the failure.

My conclusions are, that wire ligature is a safe, useful, and certain agent for conducting points of severed bone into apposition, and confining them in that condition till either that union may have taken place, or that the soft parts immediately surrounding the seat of injury shall have adapted themselves to the position of the bones. Although ligature has hitherto been applied only to cases of ununited fracture (i. e., permanently ununited), I advance the case of John Williams, No. 3, which will perhaps be admitted to show its utility in recent fractures, when the bones are very moveable; and I think it would be found very useful in military surgery or elsewhere, when the removal of the patient soon after the injury may be required, or such a necessity feared: and I would suggest the experiment of wire ligature in veterinary surgery. My present impression is, that the material of which the ligature consists does not signify. Dr. Mott has used silver and iron wires; I have used platina, copper, and iron wire, and common twine; and I bave no reason to suppose that the texture of the last had any influence on the unfarourable result of the case. I did on one occasion contemplate the using of catgut; but I feared that the knot would yield when it beeame sodden by the discharge, and so rejected it. The applicability of ligature in recent cases of fracture would bring it into a much wider field of utility than that to which it has apparently been hitherto confined. And it appears that ligature is tolerated by bone with equal patience, both in recent cases of injury and chronic cases of injury and disease.

\section{IL DIFPERENT RESOLTB OF GIMILAR INJURIES WHEN} ATTENDED BI DIFFERENT COXPLICATIONS.

My illustrations are composed of four cases of severe fractures of the tibia. Two of these turned out most satisfactorily; and two proved unsueceseful. So nearly is this sabject connocted with the former one, that I am obliged to press one of the cases already dincused into my present sesceintion; and which I shall only allude to as Case IrIor that of John Williams.

Cass v. Wm. Prickett, aged 18, receired a severe compound fracture of the leg in the summer (I believe) 1837, in a cosl or coke-yard at Merthyr Tydfil. His house being near, he was immediately conveyed there, and I was sent for. On my arrival, the limb presented as ghastly an appearance as could well be. The wound, which was on the anterior aspect of the limb, was about five inches long and gaping. The upper and lower portions of bone (the tibia) projected and crossed near their points, and were extensively denuded of their periosteum, especially the lower one. The wounds and bone were perfectly black, the latter appeared like two sticks of charcoal. The fibula was broken; there was very little hromorrhage; the soft parts at the back of the limb were not much injured. The injuries were confined to the seat of fracture and immediate neighbourhood. As the account was written from memory, I cannot state the condition of the anterior artery, but the posterior tibial was sound. The health and age of the patient being farourable, it was determined to attempt to save the limb. It was necessary to remove the ends of the bone. That of the upper portion was removed as far as the complete circumference of the bone. And that of the lower portion to the extent of an inch. The ends of the bone did not reach a state of apposition for a few days. For cometimes it was a daily duty to remedy the displacement of one or other end of the bone which occurred to about a quarter of an inch. A little sloughing ensued, suppuration was profuse, and portions of bone about the size of a finger nail exfoliated from both ends. Union took place in the ordinary period. The wound healed readily, and the limb became firmly set. There was no enlargement, or callus, and with the exception of the more rounded shape of the limb, and the shortening, no difference could be observed between it and its fellow. The young man continued to earn a good livelihood as a haulier till 1841 , when he met with an accident which caused him the loss of both his legs. This case is the one which suggested to my mind the use of ligatures in bone.

Reported in Lancet, July 13th, 1850.

CAsE vi. William Price, aged 30, a haulier, received a severe compound and comminuted fracture of the right tibia at its middle third, March 4th, 1842. The accident was caused by a heavy carriage falling on the limb. The wheel of the carriage was the immediate instrument of injury. Many splintered portions of bone were removed, and the ends of the bone were sawn off. The loss of bone produced a considerable space between the upper and lower portions, and they could not be approximated, owing to the resistance of the fibula, which was entire. The soft parts at the back of the limb had not sustained much injury, nor had any important blood-vessel been injured. Upon a consultation, it was determined to attempt to save the limb. Simple dressings were applied, and the limb was kept steady by side splints. Very little constitutional disturbance followed. A large slough of the skin over the site of fracture followed; long and free suppuration ensued; and several collections of matter were from time to time evacuated. By the beginning of June, the external wound had nearly healed. The patient's health was rery good. The leg was now placed on one of Liston's fracture apparatus to insure more quietude. . Soon afterwards, the patient experienced a sudden and severe pain at the external side of the knee, and on examination, the head of the fibula was found displaced upwards and backwards. The portions of bone, (the tibia) now came into contact. The external wound had now perfectly healed. The limb having been kept quiet for some time longer, without any sign of union taking place, the patient was desired to get up, and friction of the ends of the bone was employed, which failing to effect any good, a soton was passed through the seat of fracture, but without benofit, and the leg was amputated February 13th, 1843, immediately above the seat of fracture. The patient made a good recovery. Both ends of the bone were tipped with cartilage. The displaced head of the fibula prevented perfect flexion 


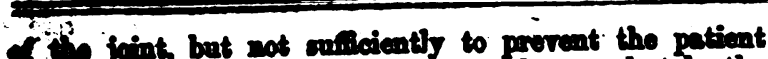
wing a rooden log. He was soon able to undertitse the intine of harnakeeper.

C19n vir. Bnnnah Jones, aged 11, was attacked with violent fobrile symptoms about the beginning of December 1849. In three days, the right leg became very much infamed and awollen. This ended in a formation of matter, which was lanced at the end of three wreeks, and a large quantity of matter escaped. It continued to discharge froely for a long time, and upon examining it with a probe, the tibis was found diseased. About four months afterwards, she fell and fractured the tibia, about an inch belor its tuberosity. No union took place, and the end of the lower portion became gradually exposed, prominent, and discoloured. It was a compound fracture. The patient's concitution was, about two months after the accident, much reakened; and upon a consultation, amputation was thought the most advisable course, which was determinately refused, and the patient was placed under the care of a quacking woman. The bone gradually became more exposed, and I was called in to remove the sequestrum, which was about six inches long; including the whole circumference of the bone at its upper end, but tapered gradually to a point at the lower one. The wound gradually healed, and the leg gradually acquired strength. The tibia was conspicuously deficient, and there was an isthmus of bone, the reverse of the sequestrum in shape, connecting the upper and lower portions. She is able to walk a distance of four or five miles, and uses neither crutch or stick.

In reviewing these cases, it will appear that in Cases IV and $v$ the loss of a large quantity of bone was no obstacle to a firm union. At the same time I would call attention to the facts of there having been in both cases a close approximation of the ends of the bone, and (I would call it) a valuable extent of surface presented at both ends of the wan bone. In Case vi, the bones were kept asunder, until the ends of the bone had become unfit for union, by the integrity of the fibula, the head of which became displaced by the efforts of the muscles, and became to some extent a permanent inconvenience. And to the sound condition of the fibula I attribute the unsuccessful result of the case. And should I again meet with a similar case, I should be disposed to divide that bone at once at the most convenient point. No attempt at union followed the approximation of the bones in this case.

Case vII is scarcely eligible to be classed with the others, as it called for no active interference of the surgeon; and probably the continuity of the tibia was never actually interrupted altogether. But it is, I think, a very singular case, its features are interesting and highly instructive. It is interesting to reflect how far the accident of fracturing the bone prevented nature reproducing a more perfectly modelled portion of bone in place of the sequestrum. I have no doubt of its having hastened the exfoliation, and prevented nature furnishing a more perfect substitute for the lost portion of bone by the injury necessarily inflicted on the shell or matrix.

Any hope of the reproduction of any quantity of lost bone from injury, founded on circumstances which attend the process of necrosis is likely, I fear, to end in disappointment; as it will appear if we take the case of W. P., Case $V I$, as a fair specimen of cases in which a considerable chasm exists between the ends of bones, that the growth of bone does not proceed to any great extent. But the ends grow tapering, granulate, and unite to soft parts, or heal orer as occurs in the stump of an amputated limb. The same condition of the ends of the bones has been remarked upon in most cases of ununited fractures. And such having been found to be the case, and a parallel between the results n cases of amputation and ununited fractures having been traced, may we not infer, with much probability, that isolation from bone is the simple cause in both instances. The isolation in ununited fracture being caused by the interpocition of a fragment of bose, or some of the coft parts. It crems to me very difficult to reconcile the idea of a physical cares of non-union, except in istems trinted with poison,

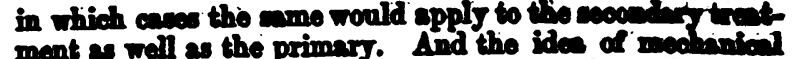
mont as well as the primary. And the ido of noomanich interposition is countenanced by the fect that an ind ments and instrumentalities which hare been found mons Supposing such to be the case, in most instances the besis of treatment becomes evident; vis., to remore the cartilaginous growth from the ends of the bones sufficiently far to obtain an adequate extent of surface of genuine bone at both ends, and to secure their contact without the interposition of anything. And I cannot imagine any mode of proceeding better calculated to obtain those ends than that which is expressed by Dr. Mott, "resection of the fragments and their union by means of wire". When approximating the bones in the case of $\mathrm{R}$. Jones, a large belly of muscle intruded itself, and it was necessary to carry the finger through between the bones to displace it. This is a liability which should also be borne in mind at the onset of the treatment of cases of severe fractures.

The theory of the process by which fractured bones unite and are repaired, appears to be undergoing revision, and is approaching, I think, much nearer to the real state of the case. The old theory of the mechanical ferrule-like agent of callus has for some time struck me as being erroneous. The opinions of Mr. Paget of London, and Dr. J. Hamilton of Buffalo, U.S., have dealt a most serere blow against the old theory. Dr. J. Hamilton (Buffalo Medical Journal, quoted in Association Mrdical Jodrnay, June 10th, 1853) says, "broken bones unite when submitted to the most farourable circumstances by definitive callus, or by a process allied to adhesion, by first intention; but under less farourable circumstances by provisional callus, or by a process allied to granulation, by second intention." I would suggest a slight alteration in the phraseology of this paragraph, by erasing the allusions to callus, and the parallels to union of other structures, and allow bones to unite by the same processes as other structures of the body, viz., by first intention or by granulation. It will be remembered that in the case of J. W., Case III, an elastic band of granulations which could be put on the stretch, was distinctly observed connecting the bones; before any other means of connexion could bo observed. And granulating bone will unite to any other granulating structure that it may chance to come in contact with-be it bone, ligament, muscular fibre, or integument; which, I imagine, would not be the case if the respective structures were governed by different physical laws.

Yerthyr Tydfil, June 1854.

\section{LEAVES FROM THE NOTE-BOOK OF A WEST INDIAN PRACTITIONER.}

\section{By LEWIS ASHENHEIM, M.D.}

I. DISRUPTED PLACENTA : gYRINGIXA THE DTERUS.

JANE TRUEWIe, a coloured, young, unmarried woman, aged about 24, was delivered of her second child on November 8th, 1853; I was informed that she had been in labour about four hours before the infant was born, and that, at the moment of birth, she was told by the midwife in attendance to raise herself up, and stand erect, by laying hold of har (the midwife's) shoulders. The girl did as she was ordered, when the umbilical cord snapped, and she felt a sensation as if "something went back into her". The midwife then introduced her hand into the vagina, and, after a little time, pulled something away, and then said that " all was right." Since her delivery, large quantities of blood were from time to time discharged, sometimes in the form of pure coagula, and sometimes in fluid blood to such a largo extent as to induce her friends to fear that she would inovitably succumb. The discharge, after a day or two, amelt very offensively, and fever was almost constantly precent.

I was sent for on the 2lat of Norember, some thirteen days after delivery. On entering the room where my par tient lay, a dintinet putrefictive odour was very ovidont. 